\title{
Association between Liver Enzymes and Dyslipidemia in Yemeni Patients with Type Two Diabetes Mellitus
}

Lotfi S. Bin Dahman ( $\sim$ lotfydahman@hu.edu.ye)

College of Medicine and Health Sciences, Hadhramout University

Mariam A. Humam

College of Medicine and Health Sciences, Hadhramout University

Omer H. Barahim

College of Medicine and Health Sciences, Hadhramout University

Omer M. Barahman

Hadhramout University

Mohamed A. Balfas

Hadhramout University

\section{Research Article}

Keywords: liver enzymes, dyslipidemia, type 2 diabetes mellitus, Yemeni Patients

Posted Date: January 15th, 2021

DOI: https://doi.org/10.21203/rs.3.rs-148386/v1

License: (9) This work is licensed under a Creative Commons Attribution 4.0 International License. Read Full License 


\section{Abstract}

Type two diabetes mellitus is characterized by chronic hyperglycemia and is associated with dyslipidemia and liver function disorders. This study was conducted to assess the association between liver enzymes and elevated lipids profile in a sample of Yemeni patients with T2DM. A case- control study comprising 142 T2D patients and 142 healthy control subjects was carried out at outpatient clinics of albn-Sina Hospital in Mukalla during the period from January to May 2020. Serum fasting blood glucose, total cholesterol, triglyceride, HDL, ALT, AST, and GGTwere analyzed using the Cobas Integra Plus 400 autoanalyzer. Also, anthropometric and blood pressure measurements were taken from each participant. T2D patients had significantly higher FBG, total cholesterol, LDL-C, and GET, while HDL-C was significantly lower in T2D patients. In correlation analysis, serum GGT was positively associated with FBG, total cholesterol, triglyceride, and LDL-C. Also, serum ALT was positively associated with FBG and triglyceride. In conclusion, higher levels of ALT and GGT could be used as the predictive biomarkers for NAFLD in T2D patients with hyperglycemia. Thus, routine screening of liver enzymes and lipid profile in T2D patients is recommended for the early detection of liver abnormalities and diminish diabetes complications.

\section{Introduction}

Diabetes mellitus is a metabolic disorder characterized by chronic hyperglycemia which results from defective insulin action and secretion or both [1]. World Health Organization projects that the number of diabetic patients will exceed 350 million by 2030 [1]. Previous data have documented liver disease is a major cause of morbidity and mortality of type 2 diabetes patients [2-3]. It is well known that the liver is a vital organ in the metabolism of carbohydrates and in maintaining glucose homeostasis during fasting and postprandial period $[2,4]$.

Non-alcoholic fatty liver disease (NAFLD) is the scope of chronic liver disease in T2D patients [5], which is characterized by excess deposition of fat in the liver and associated with hepatic insulin resistance [3] and T2D risk [5]. Serum alanine aminotransferase (ALT) and gamma-glutamyl transferase (GGT) has been shown to be good biomarkers of NAFLD. ALT has been considered the specific marker of liver injury, as found in high concentrations in hepatocytes [6], while GGT is present on the surface of most cell types and highly active in the liver, kidneys, and pancreas [7]. Also, GGT is responsible for extracellular glutathione catabolism and may be linked to oxidative stress [8] and chronic inflammation [9]; both oxidative stress and chronic inflammation are important pathways for hepatic insulin resistance (IR) and subsequently T2D development [10].

Hyperinsulinemia and IR play an important role in lipid abnormalities for T2D patients $[2,11]$. Also, altered lipoprotein patterns and liver enzymes have been identified as independent risk factors for the development of cardiovascular disease (CVD) [10-12]. Moreover, higher levels of triglycerides, LDL-C, total cholesterol, and lower levels of HDL-C were reported in T2D patients than normal healthy subjects [13]. However, few studies reported the correlation between liver enzymes and lipid profile in T2D patients, 
hence this case-control study was conducted to assess the association between liver enzymes and elevated lipid profile in a sample of Yemeni patients with T2D.

\section{Subjects And Methods}

\subsection{Study Design and Subjects Selection}

This is a case-control study was carried out at the College of Medicine and Health Sciences, Hadhramout University, and the subjects were selected from the diabetic outpatient clinic of Ibn-Sina hospital, Mukalla during the period from $1^{\text {st }}$ January to $30^{\text {th }}$ May 2020. A total of 284 Yemeni adult subjects, randomly selected, and recruited into this study. At recruitment, an in-person interview was conducted using a structured questionnaire to collect health-related information. The study group was subdivided into two groups: 142 healthy control subjects composed of 51 males and 91 females (age: $46.0 \pm 7.94$ yr.), and 142 T2D patients composed of 64 males and 78 females (age: $54.0 \pm 8.29 \mathrm{yr}$.). T2D patients were those who reported being diagnosed with T2D. Healthy control subjects were selected from the remaining participants who were free of T2D and were matched for age, sex, and dialect group with cases on a 1:1 ratio. Moreover, the selected healthy control subjects were screened for the presence of undiagnosed T2D at the time of blood donation by measuring fasting blood glucose (FBG). Healthy control subjects with FBG $\geq 7.0 \mathrm{mmol} / \mathrm{L}$ were excluded from the study. Written consent was obtained from each participant entered into the study. The study was approved by the Ethics Committee of the Medicine and Health Sciences College, Hadhramout University, Mukalla, Yemen. Patients with co-morbidities such as chronic liver disease, chronic renal disease, cardiovascular disease, and malignancy were excluded.

\subsection{Data Collection}

A questionnaire form focusing on demographic information and diabetes history was given to all subjects. The patient's demographic information, clinical presentation, medical history, and physical findings were taken from each subject. This included the patient's age, sex, smoking status (never, current or past), hypertension status (yes or no), diabetes status (yes or no) diabetes duration (years), diabetes medication, and diabetes complications. Patients were diagnosed with diabetes based on medical history, present intake of diabetes medications, or according to the American Diabetes Association (ADA) criteria [14]. Classification of Body Mass Index (BMI) was based on the World Health [15].

\subsection{Anthropometric and Blood Pressure Measurements}

Weight and height were measured following measured according to WHO guidelines [15]. Body mass index (BMI) was calculated as weight/height ${ }^{2}\left(\mathrm{Kg} / \mathrm{m}^{2}\right)$. Obese subjects were defined as $\mathrm{BMI} \geq 30 \mathrm{~kg} / \mathrm{m}^{2}$ and normal-weight subjects having a BMI of 18-25 according to WHO guidelines [15]. Patients who had a blood pressure of $\geq 140 / 90 \mathrm{mmHg}$ or were taking antihypertensive medications were diagnosed with hypertension [16]. A true healthy normal ALT level ranges from 29 to $33 \mathrm{IU} / \mathrm{I}$ for males, and 19 to $25 \mathrm{IU} / \mathrm{I}$ for females and levels above this should be assessed as described by the American College of Gastroenterology (ACG) [17]. 


\subsection{Biochemical Investigations}

Ten milliliters of the venous blood sample was obtained from consenting subjects. The blood samples were collected by vein puncture in tubes without anticoagulant. The blood samples were then transported to the laboratory immediately. The serum was separated and stored at $-20^{\circ} \mathrm{C}$ freezers till analyses. The serum samples of matched case-control pairs were randomly placed next to each other with the case/control status blinded to the laboratory personnel and were processed, and tested in the same batch. All laboratory equipment was calibrated. Thawing freezing was avoided by dividing the samples into aliquots. Plasma fasting blood glucose (FBG), total cholesterol, triglycerides, and HDL-cholesterol (HDL-C) were determined enzymatically using a chemical autoanalyzer (Cobas Integra 400 Plus, Roche diagnostic $\mathrm{GmbH}$, Mannheim, Switzerland), following the standard procedures as described by the manufacturer. Concentrations of LDL-cholesterol (LDL-C) were calculated using Friedwald's formula [18]. All biochemical investigations were analyzed in the National Center for Public Health Labs-Mukalla, Yemen.

\subsection{Statistical Analysis}

Data were analyzed using the Statistical Package for the Social Sciences for Windows (version 24) and are expressed by mean \pm standard deviation (SD) for continuous variables (normally distributed). Noncontinuous variables are expressed by median (inter-quartile range) and $n$ (percentage) for categorical variables. Independent Student's t-test used for normally distributed continuous variables and Wilcoxon signed-rank test for skewed continuous variables. The Pearson correlation test was performed with ALT, AST, and GGT as the dependent variables. The statistical analysis was conducted at a $95 \%$ confidence level and a $P$-value $<0.05$ was considered statistically significant.

\section{Results}

Descriptive statistics of anthropometric and biochemical data of the study population are presented in table 1. T2D patients had significantly increased BMI $(P=0.008)$, systolic BP $(P=<0.0001)$, diastolic BP $(P=<0.0001)$, FBG $(P=<0.0001)$, total cholesterol $(P=<0.0001)$, LDL-C $(P=<0.0001)$, and GGT $(P=0.016)$ as compared to healthy control subjects. No significant difference was found in serum triglyceride $(P=$ $0.097)$ and $\operatorname{ALT}(P=0.07)$. Healthy control subjects had significantly increased HDL-C $(P=0.021)$ and AST ( $P=0.001$ ) as compared to T2D patients. On the other hand, 31.7\% of T2D patients had hypertension, whereas, $6.3 \%$ of healthy control subjects had hypertension. Besides, in T2D patients, the current smokers were $4.2 \%$ and the former smokers were $3.5 \%$. According to BMI criteria, $38.7 \%$ of T2D patients had overweight and $24.6 \%$ with obese as compared to healthy control subjects $(40.1 \%, 14.1 \%)$ respectively.

Pearson correlation using ALT, AST, and GGT as dependent variables is presented in table 2. Serum ALT was positively associated with FBG $(r=0.145, P=0.014)$, triglyceride $(r=0.172, P=0.004)$, AST $(r=590, P=$ $<0.001)$, and GGT ( $r=0.507, P=<0.001)$ respectively. Serum GGT was positively associated with systolic $\operatorname{BP}(r=0.134, P=0.024)$, diastolic BP $(r=0.218, P=<0.001)$, FBG $(r=0.216, P=<0.0001)$, total cholesterol 
( $\mathrm{r}=0.196, P=0.0001)$, triglyceride $(\mathrm{r}=0.123, P=0.038)$, LDL-cholesterol $(\mathrm{r}=0.209, P=<0.0001)$, and AST ( $r=0.366, P=<0.0001)$ across the combined group.

Using partial correlation analysis (table 3), controlling for age and BMI, significant positive association between ALT with AST $(r=0.589, P=<0.0001)$ and ALT $(r=0.514, P=<0.0001)$ remained significant across the combined group, whilst, the association between ALT with FBG and triglyceride was no longer significant. Using the same analysis, the association between GGT with systolic BP $(r=0.124, P=0.038)$, diastolic BP $(r=0.213, P=<0.0001)$, FBG $(r=0.213, P=<0.0001)$, total cholesterol $(r=0.199, P=0.001)$, triglyceride $(\mathrm{r}=0.127, P=0.033)$, and LDL-C $(\mathrm{r}=0.208, P=<0.0001)$ remained significant before and after age and $\mathrm{BMI}$ as adjustment.

\section{Discussion}

Despite the incidence of diabetes is increasing worldwide and its prevalence is higher in developing countries, no studies have examined the relationship between liver enzymes with hyperlipidemia among T2D patients in Yemen. Additionally, most people aged $\geq 45$ years in developing countries suffer from diabetes [19]. These findings were convenient with our study showed that T2D patients had significantly higher mean age compared to healthy control subjects (Table 1). Besides, the present study observed that $\mathrm{BMI}$, systolic BP, and diastolic BP were significantly higher in T2D patients than healthy control subjects. T2D patients had significantly higher FBG, total cholesterol, and LDL-C compared with healthy control subjects. In contrast, HDL-C was significantly lower in T2D patients, whilst, no significant difference was found among both groups for triglyceride. Additionally, higher levels of GGT were revealed in T2D patients. In contrast, AST was significantly lower in T2D patients. No significant difference was found among both groups for ALT. Such a positive relationship between liver enzymes and lipid profile has been observed in previous studies [2,20-22]. Furthermore, a study by Adeniran et al. observed that ALT and AST were significantly increased with dyslipidemia in Nigerian patients diagnosed with T2DM [23].

Our study further revealed positive correlations between GGT with FBG, total cholesterol, triglyceride, and LDL-C across the combined group before and after adjustment for age and BMI, whilst, the association between ALT with FBG and triglyceride was no longer significant after adjustment for age and BMI. From the above data, our findings agree with previous studies [24-25]. This finding supports the role of hepatic insulin resistance in the pathogenesis of NAFLD $[24,26]$. Moreover, Marchesinia et al. showed an association between higher ALT levels with increased IR, blood lipids [27], and fatty liver [28] in T2D patients. Besides, a positive relationship between elevated liver enzymes with fasting and postprandial glucose was observed [29]. The liver is a vital organ in maintaining glucose homeostasis during the fasting and postprandial period $[2,4]$.

Since the liver is the important organ involved in carbohydrate and lipid metabolism and due insulin resistance is common in T2D patients, the function of the liver gets disturbed. Insulin contributes a proinflammatory effect to liver abrasion [30]. Hyperlipidemic profile is observed due to increased transportation of fat to the liver with respect to decreased oxidation [4]. The impairment of the normal 
process of synthesis and elimination of triglycerides may progress to fibrosis, cirrhosis, and hepatocellular carcinoma [31-32]. One study also reported a correlation between ALT activity and increased fatty liver [28].

GGT is known as a marker of hepatobiliary disorders and is associated with other pathological conditions like diabetes. Free radicals generated by diabetes consume glutathione which induces the increased expression of GGT in hepatocytes. Various studies have suggested the association of GGT concentrations with T2D [33-36] and hyperlipidemia [37]. These findings are in agreement with our study; GGT was significantly associated with the hyperglycemic and hyperlipidemic profile. We observed ALT and GGT together were positively correlated. Moreover, some data also reported elevated GGT levels with ALT in T2D patients with dyslipidemia $[34,35,38]$. Although we did not confirm the presence of fatty liver by ultrasound techniques, we showed the relationship of ALT, AST, and GGT with the predictors of diabetes and lipid profile parameters, presenting hepatocellular injury. In contrast, the present study showed a weak positive correlation between AST with blood glucose and lipid profile; being AST is a less specific biomarker of hepatic injury than ALT and GGT [34].

A study of male Korean workers found that AST was independently associated with diabetes [39], while in a study of male Japanese office workers AST was not associated with T2D risk [35]. Some studies also reported that ALT is a significant predictor of diabetes while AST is not $[2,40]$. These findings are in agreement with our findings as AST does not show considerable relationship with the studied parameters. However, our study is limited to the standard method of liver biopsy for the prediction of NAFLD but it goes with the analysis of the Third National Health and Nutritional Examination Survey where individuals with NAFLD are known to have elevated aminotransferases; AST, and ALT. Moreover, Clark et al. suggested that mild or chronic elevations of these aminotransferases may be due to NAFLD [41-42]. One limitation of the present study was the small sample size. Thus, further large sample size studies with more biomarkers such as insulin, hs-CRP, and adipokines are required with liver enzymes and lipid profile. Finally, we conclude that ALT and GGT are the predictive markers for NAFLD in T2D patients with hyperlipidemia.

\section{Conclusion}

Higher levels of ALT and GGT may be used as the predictive markers for NAFLD in T2D patients with hyperlipidemia. Thus, routine screening of liver enzymes and lipid profile in T2D patients is recommended for the early detection of liver abnormalities and diminish diabetes complications.

\section{Declarations}

Conflicts of Interest

The authors declare no conflicts of interest. 
Acknowledgments

The authors are grateful to Al-Huda Medical Agency, Mukalla, Yemen, for funding the study and the IbnSina Hospital, Mukalla, Yemen for technical support. Also, we are thankful to the physicians and nurses who recruited and collected the data of the participants. Special thanks to Students of Medical Laboratory Sciences Department (Ali Alqaaiti, Saleh Daiban, Sabri Barafah, Afaf Aldibani, Safa Basawaid, and Noor Zahfan) for sample collection and analysis and data entry. Special thanks to Nasiba Al-Aidros for the statistical analysis.

\section{References}

1. World Health Organization (1999) Definition, diagnosis and classification of diabetes mellitus and its complications: Report of a WHO consultation. Geneva: World Health Organization, 1999.

2. Al-Jameil, N., Khan, F. A., Arjumand, S., et al. (2014) Associated liver enzymes with hyperlipidemic profile in type 2 diabetes patients. Int J Clin Exp Pathol, 7, 4345-4349.

3. Hanley, A.J., Williams K., Festa, A., et al. (2004) Elevations in marker of liver injury and risk of type 2 diabetes-The insulin resistance atherosclerosis study. Diabetes, 53, 2623-2632. https://doi.org/10.2337/diabetes.53.10.2623.

4. Gavin, N. and Levinthal, A.S.T. (1999) Liver disease and diabetes mellitus. Clin Diabetes, 17.

5. Ballestri, S., Zona, S., Targher, , et al. (2016) Nonalcoholic fatty liver disease is associated with an almost twofold increased risk of incident type 2 diabetes and metabolic syndrome. Evidence from a systematic review and meta-analysis. J Gastroenterol Hepatol, 31, 936-44. https://doi.org/10.1111/jgh.13264.

6. Giannini, E.G., Testa, R. and Savarino, V. (2005) Liver enzyme alteration: a guide for clinicians. CMAJ, 172, 367-3 https://doi.org/10.1503/cmaj.1040752.

7. Hanigan, M.H. and Frierson, H.F., Jr. (1996) Immunohistochemical detection of gamma-glutamyl transpeptidase in normal human tissue. J Histochem Cytochem, 44, 1101-1110 https://doi.org/10.1177/44.10.8813074.

8. Turgut, O. and Tandogan, I. (2011) Gamma-glutamyltransferase to determine cardiovascular risk: shifting the paradigm forward. J Atheroscler Thromb, 18, 177-1 https://doi.org/10.5551/jat.6189.

9. Lee, D.H. and Jacobs, D.R., Jr. (2005) Association between serum gamma-glutamyltransferase and Creactive protein. Atherosclerosis, 178, 327-3 https://doi.org/10.1016/j.atherosclerosis.2004.08.027.

10. Ye-Li, W., Woon-Puay, K., Jian-Min, Y. and An, P. (2016) Association between liver enzymes and incident type 2 diabetes in Singapore Chinese men and women. BMJ Open Diabetes Research and Care, 4, e000296. https://doi.org/10.1136/bmjdrc-2016-000296.

11. Ginsberg, H.N., Zhang, Y.L. and Hernandez-Ono, A. (2006) Metabolic syndrome: focus on dyslipidemia. Obesity (Silver Spring), 14 Suppl 1:41S-49S. https://doi.org/10.1038/oby.2006.281.

12. Balaji, A.S. (2014) Serum alanine transaminases and lipid profile in type 2 diabetes mellitus Indian patient. J Diab Res, [Epub ahead of print]. https://doi.org/10.5171/2013.613176. 
13. Rajeswari, S., Kumar, A., Gandhi, M. and Swaminathan, S. (2014) Association between Lipid Profile and Liver Function Tests in Diabetic Patients. Int J Pure App Biosci, 2(4):26-31.

14. American Diabetes Association (2016) Standards of medical care in diabetes-2016. Diabetes Care, 39, 101-106. https://doi.org/10.2337/dc16-S003.

15. World Health Organization (1995) Physical status: the use and interpretation of anthropometry (1995) Report of WHO expert committee. WHO Technical Report Series, no. 854. Geneva: WHO, 321344.

16. Chobanian, A.V., Bakris, G.L., Black, H.R., et al. (2003) Seventh report of the Joint National Committee on Prevention, Detection, Evaluation, and Treatment of High Blood Pressure. Hypertension, 42, 12061252. https://doi.org/10.1161/01.HYP.0000107251.49515.c2.

17. Kwo, P.Y., Cohen, S.M. and Lim, J.K. (2017) ACG clinical guideline: evaluation of abnormal liver chemistries. Am J Gastroenterol, 112, 18-35. https://doi.org/10.1038/ajg.2016.517.

18. Friedewald, W.T., Levy, R.I. and Fredrickson, D.S. (1972) Estimation of the concentration of lowdensity lipoprotein cholesterol in plasma, without use of the preparative ultracentrifuge. Clin Chem, 18, 499-502. https://doi.org/10.1093/clinchem/36.1.15.

19. Nwarfor, A. and Owhoji, A. (2001) The prevalence of diabetes mellitus in port-Harcourt correlates with the socio-economic status. J App/ Sci Environ Mgt, 5, 75-77.

20. Jain, H.R., Shetty, V., Singh, G.S. and Shetty, S. (2016) A Study of Lipid Profile in Diabetes Mellitus. Int J Sci Stud, 4, 56-61.

21. Han, N., Soe, H.K. and Htet, A. (2012) Determinants of Abnormal Liver Function Tests in Diabetes Patients in Myanmar. Int J Diab Res, 1, 36-41. https://doi.org/10.5923/j.diabetes.20120103.02.

22. Belay, Z., Daniel, S., Tedla, K. and Gnanasekaran, N. (2014) Impairment of liver function tests and lipid profiles in type 2 diabetic patients treated at the diabetic center in Tikur Anbessa specialized teaching hospital (Tasth), Addis Ababa, Ethiopia. J Diabetes Metab, 5, 454. https://doi.org/10.4172/2155-6156.1000454.

23. Adeniran, S.A., Dolapo, P.O., Oluwole, A.B., et al. (2013) Liver Enzymes and Lipid Profile Among Type 2 Diabetic Patients in Osogbo, Nigeria. Greener J Med Sci, 3, 174-178. https://doi.org/10.15580/GJMS.2013.5.011313373.

24. Tolman, K.G., Fonseca, V., Dalpiaz, A., et al. (2007) Spectrum of liver disease in type 2 diabetes and management of patients with diabetes and liver disease. Diabetes Care, 30, 734-743. https://doi.org/10.2337/dc06-1539.

25. Idris, A.S., Mekky, F.H., Abdalla, E.E. and Ali, K.A. (2011) Liver function tests in type 2 Sudanese diabetic patients. Int J Nutr Metab, 3, 17-21.

26. Nannipieri, M., Gonzales, C., Baldi, S., et al. (2005) Liver enzymes, the metabolic syndrome, and incident diabetes: The Mexico City diabetes study. Diabetes Care, 28, 1757-1762. https://doi.org/10.2337/diacare.28.7.1757.

27. Marchesini, G., Avagnina, S., Barantani, E.G., et al. Aminotransferase and gamma glutamyl transpeptidase levels in obesity are associated with insulin resistance and the metabolic syndrome. 
J Endocrinol Invest, 28, 333-339. https://doi.org/10.1007/BF03347199.

28. Cho, N.H., Jang, H.C., Choi, S.H., et al. (2007) Abnormal liver function test predicts type 2 diabetes: a community-based prospective study. Diabetes Care, 30, 2566-256 https://doi.org/10.2337/dc070106.

29. Jayarama, N. and Sudha, R. A. (2012) Study of non-alcoholic fatty liver disease (NAFLD) in type2 diabetes mellitus in a tertiary care centre, Southern India. J Clin Diag Res, 6, 243-245.

30. Balaji, A.S. (2014) Serum alanine transaminases and lipid profile in type 2 diabetes mellitus Indian patient. J Diab Res, [Epub ahead of print]. https://doi.org/10.5171/2013.613176.

31. Tolman, K.G., Fonseca, V., Tan, M.H. and Dalpiaz, A. (2004) Hepatobiliary disease in type 2 diabetes mellitus. Ann Intern Med, 141, 946-956. https://doi.org/10.7326/0003-4819-141-12-20041221000011.

32. Chatila, R. and West, A.B. (1996) Hepatomegaly and abnormal liver tests due to glycogenesis in adults with diabetes. Med Balt, 75, 327-333. https://doi.org/10.1097/00005792-199611000-00003.

33. Lee, D.H., Silventonein, K., Jacobs, D.R., et al. (2014) Gamma glutamyltransferase, obesity and the risk of type 2 diabetes observational cohort study among 20,158 middle aged men and women. $J$ Clin Endocrinol Metab, 89, 5410-5414. https://doi.org/10.1210/jc.2004-0505.

34. Lee, D.H., Ha, M.H., Kim, J.H., et al. (2003) Gamma glutamyltransferase and diabetes-a four year follow up study. Diabetologia, 46, 359-364. https://doi.org/10.1007/s00125-003-1036-5.

35. Nakanishi, N., Suzuki, K. and Tatara, K. (2004) Serum gamma glutamyltransferase and risk of metabolic syndrome and type 2 diabetes in middle aged Japanese men. Diabetes Care, 27, 14271432. https://doi.org/10.2337/diacare.27.6.1427.

36. Lee, D.H., Jacobs, D.R., Gross, M., Kiefe Cl, et al. (2003) Gamma glutamyltransferase is a predictor of incident diabetes and hypertension: the Coronary Artery Risk Development in Young Adults (CARDIA) Study. Clin Chem, 49, 1358-1366. https://doi.org/10.1373/49.8.1358.

37. Sakuta, H., Suzuki, T., Yasuda, H. and Ito, T. (2005) Gamma glutamyltransferase and airflow obstruction in middle-aged men. Eur J Intern Med, 16, 348-351. https://doi.org/10.1016/j.ejim.2005.06.005.

38. Marchesini, G., Brizi, M., Bianchi, G., et al. (2001) Nonalcoholic fatty liver disease: a feature of the metabolic syndrome. Diabetes, 50, 1844-1850. https://doi.org/10.2337/diabetes.50.8.1844.

39. Ahn, H.R., Nam, H.S., Park, K.S., et al. (2014) The association between liver enzymes and risk of type 2 diabetes: the Namwon study. Diabetol Metab Syndr, 6, 14. https://doi.org/10.1186/1758-5996-6-14.

40. Vozarova, B., Stefan, N., Lindsay, R.S., et al. (2002) High alanine aminotransferase is associated with decreased hepatic insulin sensitivity and predicts the development of type 2 diabetes. Diabetes, 51, 1889-18 https://doi.org/10.2337/diabetes.51.6.1889.

41. Clark, J.M. and Diehl, A.M. (2003) Nonalcoholic fatty liver disease: an underrecognized cause of cryptogenic cirrhosis. JAMA, 290, 3000-3004. https://doi.org/10.1001/jama.289.22.3000. 
42. Clark, J.M., Brancati, F.L. and Diehl, A.M. (2003) The prevalence and etiology of elevated aminotransferase levels in the United States. Am J Gastroenterol, 98, 960-967. https://doi.org/10.1111/j.1572-0241.2003.07486.x.

\section{Tables}

Table1. Anthropometric and biochemical data of healthy controls and T2D patients 


\begin{tabular}{|c|c|c|c|}
\hline Variables & Healthy controls & T2D patients & $P$-value \\
\hline $\mathrm{N}$ & 142 & 142 & \\
\hline Age (years) & $46.0 \pm 7.94$ & $54.0 \pm 8.29$ & $<0.0001$ \\
\hline Sex: male/female & $51(35.9) / 91(64.1)$ & $63(44.4) / 78(54.9)$ & \\
\hline Weight (kg) & $71.12 \pm 10.67$ & $69.61 \pm 13.83$ & $<0.0001$ \\
\hline Height (cm) & $164.57 \pm 8.47$ & $159.97 \pm 10.04$ & $<0.0001$ \\
\hline $\mathrm{BMI}\left(\mathrm{kg} / \mathrm{m}^{2}\right)$ & $26.31 \pm 3.95$ & $27.21 \pm 4.94$ & 0.008 \\
\hline $\mathrm{SBP}(\mathrm{mmHg})$ & $115.28 \pm 13.11$ & $128.80 \pm 20.92$ & $<0.0001$ \\
\hline $\mathrm{DBP}(\mathrm{mmHg})$ & $70.45 \pm 9.02$ & $79.47 \pm 9.90$ & $<0.0001$ \\
\hline \multicolumn{4}{|l|}{ BMI classification: } \\
\hline Normal weight & $65(45.8)$ & $52(36.6)$ & \\
\hline Overweight & $57(40.1)$ & $55(38.7)$ & \\
\hline Obese & $20(14.1)$ & $35(24.6)$ & \\
\hline \multicolumn{4}{|l|}{ History of hypertension: } \\
\hline Yes/no & $9(6.3) / 133(93.7)$ & $45(31.7) / 97(68.3)$ & \\
\hline \multicolumn{4}{|l|}{ Smoking status: } \\
\hline Never Smoker & $142(100)$ & $131(92.3)$ & \\
\hline Current Smoker & $0(0)$ & $6(4.2)$ & \\
\hline Former Smoker & $0(0)$ & $5(3.5)$ & \\
\hline $\mathrm{FBG}(\mathrm{mmol} / \mathrm{L})$ & $5.18 \pm 0.91$ & $8.91 \pm 2.89$ & $<0.0001$ \\
\hline Total cholesterol (mmol/L) & $4.70 \pm 0.77$ & $5.16 \pm 1.20$ & $<0.0001$ \\
\hline Triglyceride (mmol/L) & $1.24 \pm 0.37$ & $1.16 \pm 0.42$ & 0.097 \\
\hline HDL-C (mmol/L) & $1.67 \pm 0.42$ & $1.57 \pm 0.34$ & 0.021 \\
\hline LDL-C (mmol/L) & $2.77 \pm 0.80$ & $3.35 \pm 1.17$ & 0.001 \\
\hline ALT (IU/L) & $13.1(8.37-19.3)$ & 11.6(7.3-16.8) & 0.07 \\
\hline AST (IU/L) & $21.2(17.8-28.7)$ & 16.4(13.3-21.7) & 0.001 \\
\hline GGT (IU/L) & $25.1(16.8-34.7)$ & $29.2(18.4-49.7)$ & $<0.0001$ \\
\hline
\end{tabular}


BMI, body mass index; SBP, systolic blood pressure; DBP, diastolic blood pressure; FBG, fasting blood glucose; HDL-C, high-density lipoprotein cholesterol; LDL-C, low-density lipoprotein cholesterol; ALT, alanine aminotransferase; AST, aspartate aminotransferase; GGT, gamma-glutamyltransferase.

Table 2. Pearson correlation using ALT, AST and GGT as dependent variables in the combined study group 


\begin{tabular}{|c|c|c|c|c|c|c|}
\hline$N=284$ & ALT & & AST & & GGT & \\
\hline & $r$ & $P$-value & $r$ & $P$-value & $r$ & $P$-value \\
\hline Age (years) & -0.046 & 0.443 & 0.010 & 0.860 & 0.047 & 0.433 \\
\hline $\operatorname{Sex}(M / F)$ & $0.119^{\star}$ & 0.046 & 0.116 & 0.050 & 0.016 & 0.789 \\
\hline Weight (kg) & -0.001 & 0.989 & -0.008 & 0.895 & -0.004 & 0.945 \\
\hline Height (cm) & 0.098 & 0.101 & 0.071 & 0.235 & -0.058 & 0.334 \\
\hline BMI $\left(\mathrm{kg} / \mathrm{m}^{2}\right)$ & -0.070 & 0.241 & -0.059 & 0.326 & 0.033 & 0.538 \\
\hline $\mathrm{SBP}(\mathrm{mmHg})$ & -0.037 & 0.533 & -0.058 & 0.334 & $0.134^{*}$ & 0.024 \\
\hline $\mathrm{DBP}(\mathrm{mmHg})$ & 0.013 & 0.830 & -0.080 & 0.178 & $0.218^{\star \star}$ & $<0.001$ \\
\hline $\mathrm{FBG}(\mathrm{mmol} / \mathrm{L})$ & $0.145^{\star}$ & 0.014 & -0.067 & 0.260 & $0.216^{\star \star}$ & $<0.0001$ \\
\hline Total cholesterol (mmol/L) & 0.027 & 0.653 & 0.081 & 0.176 & $0.196^{*}$ & 0.0001 \\
\hline Triglyceride (mmol/L) & $0.172^{\star \star}$ & 0.004 & 0.087 & 0.141 & $0.123^{*}$ & 0.038 \\
\hline $\mathrm{HDL}-\mathrm{C}(\mathrm{mmol} / \mathrm{L})$ & -0.091 & 0.124 & -0.023 & 0.699 & -0.064 & 0.285 \\
\hline LDL-C (mmol/L) & 0.047 & 0.429 & 0.082 & 0.170 & $0.209^{* *}$ & $<0.0001$ \\
\hline $\operatorname{ALT}(I U / L)$ & & & $0.590^{\star *}$ & $<0.0001$ & $0.507^{\star \star}$ & $<0.0001$ \\
\hline AST (IU/L) & $0.590^{\star \star}$ & $<0.0001$ & & & $0.366^{* \star}$ & $<0.0001$ \\
\hline GGT (IU/L) & $0.507^{\star *}$ & $<0.0001$ & $0.366^{\star *}$ & $<0.0001$ & & \\
\hline $\begin{array}{l}\text { Pearson correlation coefficie } \\
\star \star \text { Correlation is significant } \\
\text { * Correlation is significant a }\end{array}$ & 0.01 lev & $\begin{array}{l}\text { onding } p \text {-v } \\
\text { (2-tailed). } \\
\text { (2-tailed). }\end{array}$ & ue $(p<0.0$ & s consider & a signific & \\
\hline \multicolumn{7}{|c|}{ 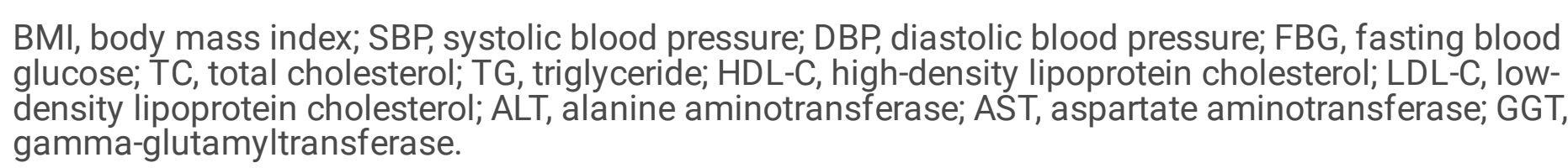 } \\
\hline
\end{tabular}

Table 3: Pearson correlation using ALT, AST and GGT as dependent variables in the combined groups studied after Age and BMI adjustment as a covariance 


\begin{tabular}{|c|c|c|c|c|c|c|}
\hline \multirow[t]{2}{*}{$N=284$} & \multicolumn{2}{|l|}{ ALT } & \multicolumn{2}{|l|}{ AST } & \multicolumn{2}{|l|}{ GGT } \\
\hline & $r$ & $P$-value & $r$ & $P$-value & $r$ & $P$-value \\
\hline $\operatorname{Sex}(M / F)$ & 0.116 & 0.051 & 0.114 & 0.055 & 0.017 & 0.772 \\
\hline $\mathrm{SBP}(\mathrm{mmHg})$ & -0.018 & 0.764 & -0.053 & 0.377 & $0.124^{*}$ & 0.038 \\
\hline $\mathrm{DBP}(\mathrm{mmHg})$ & 0.024 & 0.686 & -0.078 & 0.194 & $0.213^{* *}$ & $0<.0001$ \\
\hline FBG (mmol/L) & 0.161 & 0.007 & -0.074 & 0.213 & $0.213^{\star *}$ & $<0.0001$ \\
\hline Total cholesterol $(\mathrm{mmol} / \mathrm{L})$ & 0.027 & 0.652 & 0.085 & 0.155 & 0.199 & 0.001 \\
\hline Triglyceride $(\mathrm{mmol} / \mathrm{L})$ & 0.171 & 0.004 & 0.090 & 0.130 & 0.127 & 0.033 \\
\hline $\mathrm{HDL}-\mathrm{C}(\mathrm{mmol} / \mathrm{L})$ & -0.104 & 0.081 & -0.026 & 0.668 & -0.056 & 0.351 \\
\hline LDL-C (mmol/L) & 0.052 & 0.388 & 0.087 & 0.147 & 0.208 & $<0.0001$ \\
\hline ALT (IU/L) & & & $0.589^{\star *}$ & $<0.0001$ & $0.514^{\star \star}$ & $<0.0001$ \\
\hline AST (IU/L) & $0.589^{\star \star}$ & $<0.0001$ & & & $0.368^{* *}$ & $<0.0001$ \\
\hline GGT (IU/L) & $0.514^{\star \star}$ & $<0.0001$ & $0.368^{\star \star}$ & $<0.0001$ & & \\
\hline $\begin{array}{l}\text { Pearson correlation coeffici } \\
\text { * Correlation is significant } \\
\text { * Correlation is significant a }\end{array}$ & $\begin{array}{l}\text { with corre } \\
0.01 \mathrm{le} \\
0.05 \mathrm{lev}\end{array}$ & $\begin{array}{l}\text { (2-tailed). } \\
\text { (2-tailed). }\end{array}$ & ue $(p<0.0$ & is significa & & \\
\hline \multicolumn{7}{|c|}{$\begin{array}{l}\text { BMI, body mass index; SBP, systolic blood pressure; DBP, diastolic blood pressure; FBG, fasting blood } \\
\text { glucose; HDL-C, high-density lipoprotein cholesterol; LDL-cholesterol, low-density lipoprotein } \\
\text { cholesterol; ALT, alanine aminotransferase; AST, aspartate aminotransferase; GGT, gamma- } \\
\text { glutamyltransferase. }\end{array}$} \\
\hline
\end{tabular}

